\title{
(Q)
}

\section{Educating Things: Art Education Beyond the Individual in the Post-Digital}

\author{
Annemarie Habn
}

I am an art educator. As an art educator within an academic system, it is my profession to think about how people who are required to go to school get the skills they need in present and future societies. That sounds easy for now: Every country has curricula or similar guidelines that indicate what the responsible citizen is supposed to be able to do after school. That can, to a degree, be very helpful. It might; however, be that one essential aspect is not sufficiently taken into account in these guidelines: the current social condition in which we live, which many describe as post-digital. This is linked in part to a changed understanding of (individual) subjectivity. From the changed understanding of the subject, consequences for art pedagogical theory and practice under post-digital conditions can be derived.

My approach in this text will be to explore the question of concepts of subjectivity in post-digital societies on the basis of exhibition $\mathrm{Co}^{-}$ Workers-Le réseau comme artiste (The Network as Artist), which took place at the Musée d'art moderne in Paris (MAM) in 2015-2016. I

\footnotetext{
A. Hahn $(\bowtie)$

University of Cologne, Cologne, Germany

(C) The Author(s) 2021

K. Tavin et al. (eds.), Post-Digital, Post-Internet Art and Education, Palgrave Studies in Educational Futures, https://doi.org/10.1007/978-3-030-73770-2_13
} 
understand exhibitions as complex structures of their time. The CoWorkers exhibition is particularly suitable here, especially since it offers indications on various levels that can be used to ask questions about contemporary subject constructions. To this end, I will use posthuman and neo-materialist theoretical approaches to think about subject conditions in the post-digital. Based on this approach, I propose, at least theoretically, solutions that may provide a seedbed for a contemporary art education beyond individual subjectivity.

\section{Subjectivity In The Post-digital}

A central aspect in the exploration of subjectivity under post-digital conditions is the relationship to the respective media-cultural conditions. Culture, understood as "the processes of social meaning - that is, the normative dimension of existence"-which are "explicitly or implicitly negotiated and realized by means of singular and collective activity" (Stalder 2016, p. 7), affects the respective understanding of subjectivity. Taking seriously that conceptions of subjectivity change with the respective mass media (Meyer \& Jörissen, 2015), they also alter within the post-digital.

My proposal to think changed subjectivity and post-digitality together is to apply posthuman and neo-materialist theory to the field of art education in order to sketch an idea of subjectivity under post-digital conditions. The theoretical perspective that is to be made strong here is one that does not place the human subject at the center of the debate. Human subjects and human bodies become, with posthuman and neomaterialistic approaches, equal parts of social constitutions within the digital. When humans play a subordinate role in educational processes, this is to the benefit of nonhuman actors. In terms of pedagogical considerations, this means irritating essentialist frameworks beyond a Cartesian mind-body dualism (Hickey-Moody \& Page, 2015) in order to look more closely and more strongly at the relationship between human and nonhuman actors than at the development of individual subjects (Reddington \& Price, 2018). The turning away from the individual subject toward an entangled one is of high significance for art education in particular. This turning point can create new conditions and opportunities for (art) education that are appropriate to the recognition of various subject positions. 
New materialist theories and their implicit posthumanist approaches allow us to understand the power relations between human and nonhuman actors and thus to make a change of perspective in order to think of subjectivity from the relations of humans and things (e.g., Barad2012; Braidotti, 2013; Tuin, 2018). These approaches criticize the anthropocentric assumption that matter is by nature passive and thus in itself meaningless (Gamble et al., 2019). They do not presuppose the separateness of anything. Thus, they also question the supposed spatial, ontological, and epistemological distinction that defines the human being as something different or even superior to things (Barad, 2012). The performative approach of the new materialism, especially in Barad's agential realism, consistently refuses to separate what lies outside of matter-including human meaning-which gives it meaning only in retrospect (Gamble et al., 2019). An important point that neomaterialistic approaches make in these matters is the understanding of action and intention. Action within these connections does not necessarily have to emanate from humans. Nonhuman agents are also capable of action. In Barad's understanding, matter is an active agent. Agency is not something someone has-it rather has to be understood as relational. "Or rather, matter is an intraactive becoming that is included and folded into its gradual becoming" (Barad, 2012, p. 41). Also, intentionality, which is also traditionally tight to human subjectivity gets another notion through the lens of agential realism. Barad understands intentionality as ascribed to a complex network of human and nonhuman agents, "including historically specific sets of material conditions that go beyond the traditional notion of the individual" (p. 23).

In art educational approaches, however, the traditional figure of the individual subject still plays a significant role. More or less explicitly, the focus is on the development and formation of strong (individual) subjects instead of on the relations between humans and things (Fuchs, 2016). With regard to inclusive education in the German art education field, this figure is strengthened by approaches that refer to the concept of Künstlerische Bildung (artistic education) (Buschkühle, 2004; Engels, 2017). The figure of the self-creating artist serves here as a model, which is astonishing, especially since the traditional figure of the individual (artist) subject, has long since been questioned in post-structuralist approaches (Barthes1977; Foucault, 1969). To negotiate art education with the idea of individual subjectivity not only seems to me to be inappropriate to 
the times, but also brings with it problems of individualization of failure (Peter \& Waldschmidt, 2017) within normative school systems.

Against this background, neo-materialistic approaches become all the more relevant, especially since they seek to understand the capacity to act in the relations between human and nonhuman actors. Interestingly, most neo-materialistic and posthuman approaches do not address digitality specifically. For example, Barad's concept of agential realism (Barad, 2012) is not explicitly bound to digital conditions. It is not surprising, however, that they are becoming more popular under digital conditions, especially since traditional attributions under post-digital conditions start to falter, which are explicitly questioned in neo-materialist approaches.

In contemporary art, which explicitly deals with changed mediatechnological conditions, a changed image of (artistic) subjectivity appears, more as complex, relational subject formations than as individual ones (Herlitz \& Zahn, 2019). In order to understand how these subjectivities are revealed, in the following I will take a closer look at settings within contemporary art in which these shifts become apparent. Through the lens of neo-materialist approaches, I will analyze the exhibition Co-Workers-Le réseau comme artiste. I choose exhibitions as research material because they are complex. They cannot be reduced to their components, such as the exhibits on display or the participating artists. Nor can they be reduced to the space in which they take place or to the idea that led to their realization. As the curator and art historian Elena Filipovic (2013) writes, they are also the relationships that exist between all these elements, the dramaturgy around them, and the discourse that frames them.

In order to trace the relationships between various human and nonhuman actors under post-digital conditions, I first look at the structures and the exhibits of the exhibition on the basis of its discourse material. ${ }^{1}$ I will then take a closer look at the title of the exhibition, from which a clear shift in perspective regarding artistic production can be seen. This analysis is intended to question common concepts of subjectivity, in the hope of triggering derivations for art educational questions.

\section{LOOKING ON Co-Workers. Network as ArTisT}

Co-Workers-Le réseau comme artiste (The Network as Artist) took place at the Musée d'art moderne in Paris (MAM) in 2015-2016. Against the background of changed forms of communication through digitalization, 
the exhibition examined the question of which changes artistic production is undergoing. It primarily showed positions whose practices are characterized more by networks and their exchange than by individual artistic creative processes and thus displaces the anthropocentric position of the (artists) subject. The shift from individual artistic positions to networked and interwoven structural settings can be described on at least three levels of the exhibition: (1) the organizational level, (2) the level of artistic production, and (3) the level of the title of the exhibition.

\section{First Level: The Structures}

The first level of the Co-Workers Exhibition that seems relevant to me here is its organizational structure. The exhibition was curated by three curators: Angeline Scherf, Toke Lykkeberg, and Jessica Castex. For the mise en scène of the exhibition, the DIS Collective, with its protagonists Lauren Boyle, Solomon Chase, Marco Roso, David Toro, Nick Scholl, Patrik Sandberg, and Samuel Adrian Massey was engaged. The exhibition took place at the MAM in Paris, which was the initiator and primary venue, albeit not the only one. Simultaneously, the BétonsalonCentre d'art et de recherche hosted the co-exhibition Co-Workers: Beyond Disaster, curated by Mélanie Bouteloup and Garance Malivel, which included, in addition to the exhibition program, lectures, workshops, and other discursive formats to negotiate alternative perspectives of non-anthropocentric approaches.

A third partner was the Residency Program 89plus, founded in 2014 by Hans Ulrich Obrist and Simon Castets-an international, multi-platform research project, investigating the generation of innovators born in or after 1989. ${ }^{2} 89$ plus had been invited to initiate several 15-day solo and duo exhibitions as special interventions within the exhibition.

Already on the organizational level a collaborative structure becomes visible. But as well on a spatial and institutional level, several actors were collaboratively connected in the exhibition. Even from these superficial descriptions, the question arises whether this is an exhibition network, or whether the network itself is the exhibition.

\section{Second Level: The Artworks}

The center of the exhibition at the MAM is the installation of the DIS collective The Island (KEN). KEN is a fully functional hybrid of kitchen 
and bathroom, equipped with several screens. The kitchen and bathroom are combined in one room, even in a furniture arrangement. The installation combines the social space of the kitchen and the private bathroom (DIS, 2015) in one object. An aesthetic similar to that of high-end stock photography is applied to an installation here-a kind of rendering of "real life" as Lauren Boyle (2016) describes it in an interview with Mike Meiré. The installation not only irritates traditional spatial categories, but also creates a space for discourse in the exhibition. It serves as a place for discussions and encounters. Furthermore, the video and performance program of the exhibition is shown on its screens. The work was created in cooperation and implementation with the company DORNBRACHT, a company for high-quality furnishing and living solutions, and was thus placed in a space both inside and outside the art system. The artistic positions shown in the exhibition ${ }^{3}$ can each be understood as collaborative practices, based on networking, which are condensed in the exhibit and the exhibition space. The collaborative work, The Island (KEN), therefore seems to me to take on a reinforcing and mediating function in relation to the many other exhibited positions.

The following two examples of the exhibition illustrate this entanglement of network practices in very different but particularly explicit ways: the works by Mark Leckey and Cecile B. Evans. The framework offered by the DIS collective of the interweaving of the art and business worlds, and the resulting intertwined detachment from the art world as its own and the artist's image as a solitary entity, is shown on a visual level in Mark Leckey's work Pearl Vision (2012). The title already refers to the protagonist of the work: a snare drum by the renowned drum company Pearl. The drummer, of whom only the abdomen in red pants can be seen operating the snare drum becomes the object of the instrument. The highly technical functional mechanisms of the tool, the drums, are more in the center than the drummer. The drummer becomes the operator of the device. From minute 2 on, of the approx. 3 -minutes video, the drummer's legs are undressed. His skin is reflected in the metal of the drum. They become one, before the snare drum floats detached from the human actor in free (black-backed, computer animated) space.

The video ends with the label of the manufacturer: Pearl Drum Vision Series: Next Level Perfection. Anais Lepage describes the relationship between the diverse actors in the work as "seen through the same prism" (Lepage, 2015b, p. 112, translation by AH). This would make them part of a central reflection on the relationship between human and machine. In 
Mark Leckey's work, the constant interaction between humans and technology is described on a level that represents in a non-hierarchical way how human-nonhuman networks function.

The work by Cecile B. Evans goes one step further in terms of humanmachine networks. Working on what the heart wants (2015) is a kind of beta version of the work What the heart wants, shown one year later at the 9th Berlin Biennale, also curated by the DIS collective. The work consists of a 3-channel installation and some artifacts reminiscent of the artist's studio. Through a chat visible on the screens, Evans is in exchange with various other actors in order to realize the final version of the artwork. The installation not only demonstrates the emergence of the new work, it is artistic work and process simultaneously. Evans searches via chat with the nickname HEARTWANTS123D for collaborators and distributes tasks within the framework of the artwork. The process of cooperation is exhibited.

In What the heart wants, a kind of autobiography of HYPER, a supraindividual fictitious "person," which constantly evolves as the amount of data increases, is narrated (Lepage, 2015a). In the Working on piece it becomes visible how different human and machinic actors are involved in the realization of HYPER across time axes (Casavecchia, 2016). This example shows how artistic production in digital conditions is subject to network logic. The artist is not the sole creator of the artwork, and the artwork is not a self-contained creation, but rather a version of an ongoing process. Nevertheless, the figure of the artist continues to exist and be present in the Co-Workers exhibition, specifically in her/his naming as an artist. But if the artist's name is no longer equivalent to the person who creates the work of art, how can its function be understood? How about understanding artist names not as an individual attribute, but rather in the logic of brands, as a proxy for the network that produces the artwork, and thus as a promise of quality?

In Cécile B. Evans' installation several variations of the artist name coexist, on different levels of the work. She uses the nickname HEARTWANTS123D rather than her real or artist name to communicate with her collaborators. Here, the project name is enriched by a $123 \mathrm{~d}$, which may refer to a variety of actors involved. And this examination is also reflected on a narrative level: the work What the heart wants and the Working on version show various human and machinic agents who, across time axes, are involved in the realization of a supra-individual fictitious “person” HYPER (Casavecchia, 2016). Cécile B. Evans thus examines 
what it means to be human in the digital age and how machines define our humanity. What the heart wants does not offer us a narrative of and about individual subjects. The work is about a new form of subjectivity influenced by current technologies.

Still, using a name-giving artist as an equivalent for a project name could still be understood to mean that the artist represents the center of the respective project. The name of the exhibition "Co-Workers. Network as Artist," however, shows a shift in focus. Moving away from the centering of human agents toward the connections, the exhibition focuses on the network, and networks do not only consist of humans but several entangled human and nonhuman agents. This inevitably shifts the position of the artist within art production in favor of network structures. All the more obvious is the choice of title for the exhibition "Co-Workers. Network as artist," that brings me to the third aspect of the exhibition that is relevant to this argumentation.

\section{Third Level: The Title}

The aspect called the third level is probably the most important one, especially since it appears first on all discursive levels, in the various newsletters, on the homepage, on the catalogue, and on the billboards of the exhibition site itself: Co-Workers. Network as artist. The first part of the title "Co-Workers" addresses the workplaces that have become fluid. People work in Apple stores, Starbucks wi-fi areas, shopping malls, and airports. Both private and public life no longer contradicts work (DIS, 2015, p. 25). But with changed working conditions and with it the blurring of the boundaries between private and working space, the title is not sufficiently explained-nor is the exhibition. Co-Workers also discusses collaboration in artistic work and thus puts the traditional figure of the artist as an autonomous genius in the background in favor of common and shared artistic processes of work, in which several actors are involved.

The second part of the title Network as Artist determines the main focus of the exhibition. Remarkable here is not only the choice of the words, but their order. It is not the artist as network, but the network as artist. While the role of the artist with the formulation of the "artist as" has undergone some transformations, from the artist as producer (Benjamin, 1934) to the artist as consumer (Groys, 2003) - and various variants of these forms (Lykkeberg, 2015) - the exhibition with its title reverses this relationship. It turns the network into an acting subject 
instead of a discussed sujet as Meyer describes in his chapter in this book and elsewhere (Meyer, 2015). The network that is not necessarily bound to human actors becomes the artist here. It is not the condition or result of art, but its subject.

If we understand networks as artists with the exhibition, the misunderstanding could arise that networks, like artists, have human characteristics, which is not necessarily the case. If we do not regard subjects as synonyms for human beings and understand humans exclusively not as individuals but as interwoven with their environment, might we ask ourselves, as the works of Leckey and Evans have shown, who or what constitutes this environment and what role it plays in the constitution of the subject? We might then have to ask similar questions to the specific figure of the artist subject.

According to the vocabulary of Actor-Network Theory (ANT), an actor is not defined by his or her characteristics, human abilities, or attributes (e.g., Latour, 2014). ANT largely avoids the concept of the subject in favor of the actor and treats human and nonhuman actors equally on the conceptual level. The basic idea of ANT is that actors do not exist a priori, but are only made into actors through the formation of networks (Peuker, 2010). Here, however, networks are not exclusively social networks that develop social actors (humans), but also material ones (things) and discursive artifacts. When Bruno Latour (2014), for example, speaks of "social," he means it as a relational term, that is as associations between heterogeneous components. The individual is then the result of many heterogeneous entanglements and processes. Actors, as well as individuals, are not preceding their networking, they are just produced by the networking process. It is thereby important that both humans and things, as well as discursive artifacts, are attributed the capacity to act in the sense of agency, even if the agency is not evenly distributed (Peuker, 2010).

Even though the title of the exhibition invites associations with ANT, the observed relational structures are better characterized by neomaterialistic approaches. Because the agent in agential realism, in the sense of agency, is not originally defined, it does not even exist, but is literally a mediator (Barad, 2012). That means, always depending on their circumstances and conditions, and these conditions change, as we have seen before, with media-technological shifts. To illustrate the entanglement of the various human and nonhuman agents and their processual nature with a different linguistic figure, Barad invents the term intra-action. 
The argumentation that the use of the prefix "inter" in terms such as "interrelations" or "interactions" presupposes the prior existence of various isolated entities, emphasizes the concept of intra-action that entities only arise in relation. So there are no entities before the relation (Kleinman \& Barad, 2012). The separation of subjects and objects only occurs through interruptions of intra-actions, so-called "agential cuts" (p. 88). One could say that this separation of subjects and objects such as artists and their works, and students and their works, only emerges within the networks - through agential cuts. Identities, for example, will not be thought of as primarily existing but as effects of process and performance that become meaningful within certain structures.

The idea of the individual subject is then always dependent on its intraactions of human and nonhuman actors. But this cut certainly happens differently under different media-cultural conditions. Thus, the postdigital subject is different from subjectivity in other media-technological periods.

\section{Network as Subject}

The example of the CoWorkers exhibition, seen through neo-materialistic lenses, offers links to think subjectivity no longer from the individual, but from the network or respectively the intra-actions. Because the exhibition has negotiated a new understanding of the artist subject and artistic production since digitality, it is no longer about solitary artists who create an object or a work of art, but about interwoven practices in which human and nonhuman actors are equally involved.

With the main aspects of the new materialism (in Barad's sense) under post-digital conditions, I would like to take the following perspective on the Co-Workers exhibition. On the one hand, the exhibition is created under current media-cultural conditions. On the other hand, it does not arise through the artists' work on the works shown. Rather, both artists and artworks are only made into artists and artworks within the exhibition through intra-actions. It is therefore not the human subject that produces an external object. In that sense also other human and nonhuman actors as curators and exhibition spaces arise within the intra-actions. The dualism of subject and object is only produced by certain practices. With the exhibition "network as artist" exactly these performative acts of becoming art are exhibited and negotiable. 
Thinking about networks as artists, the question arises as to who actually contributes to certain artistic productions in what quantity and also in what quality. What role do the human actors, the material actors, and the networks play? This is where the traditional view of the artist's subject begins to falter. Who or what is it that we understand as subject? Is it perhaps more productive to talk about the network as artists in order to question the power relations between people and things more precisely? These questions to the artist subject can be transferred experimentally to subjects of art education. For if we do not only project the ability to act into individual humans, but also into the relationships between humans and things, new parameters for pedagogical thinking arise.

The exhibition makes visible what is theoretically addressed in neomaterialistic approaches. Under post-digital conditions, we are dealing in exhibition practice with altered forms of subjectivity. The practices observable there are hardly to be described in dualistic categorizations such as subject and object. The post-digital as a current cultural condition allows us to examine culture for new understandings of bodies and subjects within the social. I consider this understanding particularly productive for art pedagogical thinking. It is important to recognize, first of all, that human subjects, human bodies and also their objects become what they are in current networks, such as the educational. As a result, we consider human agents as intentional in their actions detached from their relational structures. In doing so, the nonhuman agents are attributed a passive role in which their meaning is undermined. This leads to an exclusion thinking of singular human beings instead of the focus of exclusive structures.

If the subject of art changes through post-digital changes in subjectivation, concepts in art education must also be considered. To no longer think of subjects exclusively from the perspective of the human individual means, in the final consequence, that we, as art educators, must also include the nonhuman actors - the spaces, the things-in art educational concepts, and not just as passive features, but as active participants. Not only people, but also things must be educated, so that art education in the post-digital era can prosper in a contemporary manner. This means looking beyond the individual subject, observing relations of people to other people and things, and doing so on an equal footing, and from this conceptualizing art education. For if we no longer consider the human being as capable and normative, but always think in relation to nonhuman agents, other perspectives open up and with the other potentials for action-and thus agency. 


\section{Notes}

1. Unfortunately, the exhibition catalogue (Abu Abdallah et al., 2015), which was gratefully made available by the MAM as a PDF for research purposes, presents only a few of these positions explicitly, which is interesting and relevant from a discourse-theoretical point of view, but therefore allows only a selective view of the relations of the exhibition, that is, of my interpretation of what the exhibition organizers show as valuable for communication and archiving.

2. https://www.89plus.com/about/.

3. namely, 89plus, Aids-3D, Sarah Abu Abdallah \& Abdullah Al-Mutairi, Ed Atkins, Trisha Baga, Darja Bajagić, Ian Cheng, DIS, Douglas Coupland, David Douard, Cécile B. Evans, Valia Fetisov, GCC, Parker Ito, Clémence de La Tour du Pin \& Agatha Valkyrie Ice (Dorota Gaweda, Egle Kulbokaite), Mark Leckey, Shawn Maximo, Nøne Futbol Club, Christopher Kulendran Thomas, Aude Pariset \& Juliette Bonneviot, Pin-Up, Rachel Rose, Bunny Rogers, Bogosi Sekhukhuni \& Tabita Rezaire, Timur Si-Qin, Jasper Spicero, Hito Steyerl, and Ryan Trecartin.

\section{REFERENCES}

Abu Abdallah, S., \& Souverain, A. (2015). Co-workers: le résean comme artiste. Musée d'art moderne de la ville de Paris.

Barad, K. (2012). Agentieller Realismus. Über die Bedeutung materielldiskursiver Praktiken. In Agentieller Realismus Über die Bedeutung materielldiskursiver Praktiken (unseld 45). Suhrkamp.

Barthes, R. (1977). The death of the author, translated by Stephen Heath. Image, music, text: Essays selected and translated by Stephen Heath. https://doi.org/ $10.1136 /$ bmj.a2717

Benjamin, W. (1934). The author as producer.

Boyle, L. (2016). Mike Meiré and Lauren Boyle about "The Island (KEN)" Youtube. https://www.youtube.com/watch?v=GwDWbzxTvA4.

Braidotti, R. (2013). The posthuman. polity press.

Buschkühle, C. P. (2004). Kunstpädagogen müssen Künstler sein. Zum Konzept künstlerischer Bildung. In Kunstpädagogische Positionen (Vol. 5).

Casavecchia, B. (2016). Cécile B. Evans's "working on what the heart wants." Art Agenda. https://www.art-agenda.com/reviews/cecile-b-evans\%25E2\% $2580 \% 2599$ s- $\% 25 \mathrm{E} 2 \% 2580 \% 259$ Cworking-on-what-the-heart-wants $\% 25 \mathrm{E} 2 \%$ $2580 \% 259 \mathrm{D} /$.

DIS. (2015). Coworking DIS: mise en scène. In Musee D'Art Moderne de la Ville de Paris (Ed.), Co-workers. Le réseau comme artiste. Exhibition-catalogue (pp. 24-29). https://www.forbes.com/sites/ 
Engels, S. (2017). Inklusion und Kunstdidaktik heute. In S. Engels (Ed.), Inklusion und Kunstunterricht. Perspektiven und Ansätze künstlerischer Bildung (pp. 11-28).

Filipovic, E. (2013). What is an exhibition? In J. Hoffmann (Ed.), Ten fundamental questions of curating (pp. 71-81). Mousse Publishing.

Foucault, M. (1969). Was ist ein Autor? In F. Jannidis (Ed.), Texte zur Theorie der Autorschaft (pp. 198-229). Reclam.

Fuchs, M. (2016). Das starke Subjekt. kopaed.

Gamble, C. N., Hanan, J. S., \& Nail, T. (2019). What is new materialism? Angelaki-Journal of the Theoretical Humanities, 24(6), 111-134. https://doi. org/10.1080/0969725X.2019.1684704.

Groys, B. (2003). Der Künstler als Konsument. In B. Groys (Ed.), Topologie der Kunst (pp. 47-58). Hanser.

Herlitz, L., \& Zahn, M. (2019). Bildungstheoretische Potentiale postdigitaler Ästhetiken-Eine methodologische Annäherung. https://www.kubi-online.de/ artikel/bildungstheoretische-potentiale-postdigitaler-aesthetiken-methodolo gische-annaeherung.

Hickey-Moody, A., \& Page, T. (Eds.). (2015). Arts, pedagogy and cultural resistance: New materialisms. Rowman \& Littlefield.

Kleinman, A., \& Barad, K. (2012). Intra-actions. Mousse, 34. Retrieved from https://www.academia.edu/1857617/_Intra-actions_Interview_of_Karen_ Barad_by_Adam_Kleinmann_

Latour, B. (2014). Eine neue Soziologie für eine neue Gesellschaft. Einfülunng in die Akteur-Netzwerk-Theorie. Suhrkamp.

Lepage, A. (2015a). Cecile B. Evans. In MuseeD'Art Moderne de la Ville de Paris (Ed.), Co-Workers. Le résean comme artiste. Exhibition-Catalogue (pp. 100-103).

Lepage, A. (2015b). Marc Leckey. In Musée d'art moderne de la ville de Paris (Ed.), Co-Workers. Le réseau comme artiste. Exbibition-Catalogue (pp. 112113 ).

Lykkeberg, T. (2015). Le réseau comme artiste. In Musee D’Art Moderne de la Ville de Paris (Ed.), Co-Workers. Le réseau comme artiste. Exhibition-Catalogue (pp. 20-23).

Meyer, T. (2015). Ein neues Sujet. In B. Jörissen \& T. Meyer (Eds.), Subjekt medium bildung (pp. 93-116). Springer VS.

Meyer, T., \& Jörissen, B. (2015). Subjekt, Medium, Bildung-Vorwort. In T. Meyer \& B. Jörissen (Eds.), Subjekt, Medium, Bildung (Medienbild, pp. 717). https://doi.org/https://doi.org/10.1007/978-3-531-18905-5.

Peter, T., \& Waldschmidt, A. (2017). Inklusion. Genealogie und Dispositivanalyse eines Leitbegriffs der Gegenwart. Sport Und Gesellschaft, 14(1), 29-52. https://doi.org/https://doi.org/10.1515/sug-2017-0003. 
Peuker, B. (2010). Akteur-Netzwerk-Theorie (ANT). In C. Stegbauer \& R. Häußling (Eds.), Handbuch Netzwerkforschung (Netzwerkfo, pp. 325-337). Springer VS.

Reddington, S., \& Price, D. (2018). Pedagogy of new materialism: Advancing the educational inclusion agenda for children and youth with disabilities. Disabilty Studies Quarterly, 38. https://dsq-sds.org/article/view/5945/ 4879

Stalder, F. (2016). Kultur der Digitalität (2nd ed.). Suhrkamp.

Tuin, I. van der. (2018). Neo/New materialism. In M. Braidotti, Rosi \& Hlavajova (Ed.), Posthuman glossary (pp. 277-279). Bloomsbury Academic.

Open Access This chapter is licensed under the terms of the Creative Commons Attribution 4.0 International License (http://creativecommons.org/licenses/ by $/ 4.0 /$ ), which permits use, sharing, adaptation, distribution and reproduction in any medium or format, as long as you give appropriate credit to the original author(s) and the source, provide a link to the Creative Commons license and indicate if changes were made.

The images or other third party material in this chapter are included in the chapter's Creative Commons license, unless indicated otherwise in a credit line to the material. If material is not included in the chapter's Creative Commons license and your intended use is not permitted by statutory regulation or exceeds the permitted use, you will need to obtain permission directly from the copyright holder.

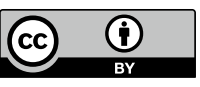

